\title{
Making research visible A library competition for graduate students
}

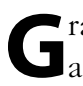
aduate students have always been a core academic library user group. However, because undergraduates typically make up a larger percentage of the on-campus student body, the development of targeted library services and programming for graduate students has often taken a back seat. Recently, however, interest in academic library services for graduate students has increased, as demonstrated by conferences devoted to this topic ${ }^{1}$ and the formation of an ACRL interest group focused on this issue. ${ }^{2}$

One way libraries have supported undergraduates is by rewarding and showcasing their research outputs through research award competitions. Oregon State University Libraries, has held a Library Undergraduate Research Award competition for many years ${ }^{3}$ and similar competitions can be found at Penn State University ${ }^{4}$ and the University of Washington, ${ }^{5}$ to highlight a few.

Other libraries, such as the University of Southern California ${ }^{6}$ and Brandeis University, ${ }^{7}$ invite both undergraduate and graduate students to take part in these competitions. These awards seek to highlight the connection between using library resources and services and the excellent research papers that can result. When we considered the types of research and scholarship graduate students do and the changing nature of academic library research, we wondered if a competition that focused on the process of scholarship rather than the end product might provide both graduate students and librarians with novel ways to demonstrate the impact of our work.

One major change in how graduate students interact with sources is that they may never physically interact with either the academic library collection or the library itself. As a result, library collections may begin to seem invisible, and the costs of maintaining these collections can become invisible, as well. Similarly, the impact of past scholars can feel increasingly ephemeral, and past scholarly outputs can easily recede into the constant cycle of knowledge being created. We wanted to help reveal the impact of previous researchers and their impact on graduate students' work, as well as make visible libraries' role in supporting emerging researchers. So we designed a competition to encourage graduate students to create visual representations of how past scholarship connected to their own research.

Bibliographies are one manifestation of the research conversations graduate students surface and curate. We invited graduate students from our institution to

\footnotetext{
Kalli Damschen is formerly Oregon State University Libraries graduate research assistant, email: kmdamschen@gmail.com, and Hannah Gascho Rempel is science librarian at Oregon State University, email: hannah.rempel@oregonstate.edu
}

(c) 2019 Kalli Damschen and Hannah Gascho Rempe 
participate in a competition called "Visualize Your Bibliography." The competition parameters were fairly open: creatively display at least 20 sources used in your thesis, dissertation, or other long-form project. In this article we will detail the development of the competition, share the promotion and evaluation workflows, and discuss future potential iterations of this competition.

\section{Developing the competition}

First, we proposed the competition to our library

administra-

tion. We re-

INTRODUCTION

quested in-

centives to

encourage

graduate

students

to partici-

pate. Based

on other

research

competi-

tions and

s cholar-

ships ad-

vertised on

c a m pus,

we sug-

gested and

were given

f u n d i n g

from gift

The Female Relations of Victorian England

money for

the following awards: First Place: \$750;

Second Place: \$500; Third Place: \$250.

Participants needed to be current Oregon State University graduate students. However, rewarding the process of research had the added benefit of allowing graduate students who had not yet finished their theses or degrees to take part in the competition.

Because of the novelty of this competition, we couldn't find examples of similar competitions on our campus or elsewhere.
After developing a general outline of the project's purpose and scope, we brainstormed possible submission ideas in order to develop samples, both so we would be better equipped to delineate the competition's requirements and so interested students would more clearly understand what the judges would be looking for. We generated an initial list of more than 20 different ideas, ranging from papier-mâché using pages from each source to a Tumblr blog featuring posts for each source to a family tree illustrating the connections between sources.

Out of the 20 initial sample ideas, we se lected three to create and feature on the competition's website. While selecting the sample $\mathrm{s} \mathrm{u} \mathrm{b} \mathrm{m}$ i s sions, we prioritized variety, not only in response to the quest i n of p h y s i c a l versus digital, but also by considering how students in different disciplines might approach the competition.

For the first example, we created a series of erasure poems by printing out the first page of 20 sources from the bibliography of an English thesis and erasing text from each page to create poems (see Figure 1). Both individually and as a series, the erasure poems set out to demonstrate how a scholar draws from the conversations in previous works to create something entirely new. 
For the second example, we gathered more than 30 print books from a history thesis and used them as dominos, arranging them in various configurations and then knocking them down. In addition to visually showcasing the number and variety of books cited, the resulting book dominos video also symbolically conveyed how one source can lead to another and how different ideas may intersect and collide throughout the research process (see Figure 2).

With the third example, we went entirely digital and created an online timeline of sources from a chemi s t r y dissertation, providing informa$\mathrm{t}$ i o $\mathrm{n}$ a b o u t w h e $n$ a $\mathrm{n}$ d w h e r e e a c h



Figure 2. Sample visualization using a book dominos video. tion guidelines as a way of encouraging students to think outside the box. Google Forms allows the upload of documents, spreadsheets, PDFs, videos, presentations, drawings, images, and audio files. In addition, competition participants could instead submit a link to an external website that hosted their submission. By including a range of sample submissions-one series of images, one video, and one link to a timeline-maker website-and highlighting the various file types accepted by Google Forms, we hoped to encourage students to think widely and engage their creativity in source

was published. In addition to showing the historical range of the sources, this example also revealed some interesting trends in the research, as many of the sources were published in waves, thereby highlighting the conversational element of research, as sources may respond directly or indirectly to other published materials.

The process of creating these examples helped us better understand the competition parameters by prompting us to consider a wide range of possible visualizations. For example, only after creating the examples did we settle on the mode of submission-Google Forms-because we could better anticipate what file types and sizes students might submit. Indeed, we intentionally highlighted the file types accepted by Google Forms in the competi- order to best represent $\mathrm{th}$ e i r experience of research conversations within $\mathrm{t}$ h e i r field.

Cre a $\mathrm{t}$ i $\mathrm{n} \mathrm{g}$ sample visualizations also helped us realize that to fully understand the visualizations, we would need some context. In addition to submitting the visualization, we asked participants to share a description of why they chose to display their sources the way they did and to give some background on their research project. The written submission components combined were not to exceed one page. Participants also submitted the bibliography of the sources used.

\section{Promoting the competition}

Once we finalized the competition rules, submission guidelines, and award information, we were ready to start promoting this brand new competition. To start, we populated a LibGuide $^{8}$ with all the relevant information about the contest, as 
well as the three sample submissions and a brief contextual write-up about each one. We then designed a poster featuring a summary of the competition, the award information, and the deadline, as well as a bit.ly link to the LibGuide. We emailed this promotional poster to the Graduate School, and subject liaison librarians sent it to various schools and colleges at the university. In collaboration with the Graduate School, we set the submission deadline for the first day of their annual Grad Student Appreciation Week. They agreed to include details about the competition in their promotional emails and featured information about the competition on their website in the months leading up to the deadline. Finally, we printed the promotional poster and displayed it in the library foyer.

\section{Competition participation}

Over five months, the competition's website received more than 650 views, and by the time the deadline arrived, 19 students had entered-more than twice as many entries as we anticipated for the competition's inaugural year. We selected five judges (three librarians with differing disciplinary backgrounds and two graduate students who work with the library), all of whom were blown away by the insight, skill, and originality of the 19 submissions.

For example, one student from the College of Forestry created a mobile of miniature books folded from the first page of each of her sources, and in her rationale, discussed how the mobile signified the importance of research in maintaining the delicate balance of ecosystems. A Speech Communication student created an artfully crafted video showing piles of dirt flying upward to reveal a line of books underneath. His rationale argued that good research unearths truths that might otherwise be forgotten.

Though the choice was difficult, our committee of judges used a rubric to select the three winners. The rubric included an evaluation of the originality of the visualization, the quality of the visual representation, and how the choice of the visualization conveyed interesting insights about the research process or the specific field of research. After seeing the incredible range of submissions, we determined to showcase all the entries in a gallery. After obtaining the entrants' permission, we created an online gallery ${ }^{9}$ to showcase the submissions and are currently working to put together a physical gallery, including both printed and digital visualizations. Image-based visualizations will be printed, mounted, and displayed on standing or table easels, depending on their size. Multimedia-based visualizations, such as videos and slides, will be displayed on securely mounted iPads. The visualizations will be displayed in the Graduate Student Commons, located on the sixth floor of the library.

\section{Takeaways}

Feedback from the "Visualize Your Bibliography" competition has been overwhelmingly positive. The participating graduate students were excited to see the work submitted by their peers. Library staff have been impressed by the range of visual expressions students chose. Librarians don't always get to see the final product of students' work, so the chance to gain insights into students' creative engagement with sources has been rewarding. But perhaps most importantly, this competition has allowed graduate students to re-envision their research process.

One competition participant shared that creating the visualization helped her to see her own research in a new way, which has spurred a new research direction for her. Another participant shared that the competition inspired him to think about how

(continues on page 579) 


\section{Notes}

1. Small Business Administration Office of Advocacy, "United States Small Business Economic Profiles for 2018," 2018, https://www.sba.gov/sites/default/files /advocacy/2018-Small-Business-Profiles-US. pdf.

2. CB Insights, "The Top 20 Reasons Startups Fail," (February 2, 2018), https:// app.cbinsights.com/research/startup-failure -reasons-top/.

3. Pearl Dahmen and Eileen Rodríguez, "Financial Literacy and the Success of Small Businesses: An Observation from a Small Business Development Center," Numeracy 7, no. 1 (2014), https://doi.org/10.5038/1936 -4660.7 .1 .3 .
4. Invent Penn State, "Impact," 2019, https://invent.psu.edu/impact/.

5. Penn State University, "Intercollege Minor in Entrepreneurship and Innovation," accessed May 13, 2019, enti.psu.edu/.

6. Ibid. "Penn State Startup Week," 2019, https://startupweek.psu.edu/.

7. Penn State Small Business Development Center, accessed June 4, 2019, https://sbdc. psu.edu/.

8. America's Small Business Development Centers, accessed May 30 2019, https:// americassbdc.org/.

9. Pennsylvania State Educators Credit Union, 2019, "Wallet Works Financial Education," https://www.psecu.com/learn /wallet-works. $\approx$

("Making research visible," cont. from page 572)

creative modes of communication might help his research impact new audiences in meaningful ways.

A third competition participant observed that creating a visualization in a new medium helped her tackle her feelings of imposter syndrome and gave her courage on her journey to becoming a university professor.

As library collections and services evolve, we will need to continue to think of new ways to engage with the communities we serve. Making the process of research more visible through a visualize your bibliography competition is one creative way to encourage scholarly communities to engage with their sources, reflect on the connections they have made to past scholarship, and share tangible outputs with the academic community.

\section{Notes}

1. "National Conference on Graduate Services Kennesaw State University," accessed May 22, 2019, https://digitalcommons. kennesaw.edu/gradlibconf/.

2. "ACRL Academic Library Services for Graduate Students Interest Group," accessed
May 22, 2019, https://acrl.libguides.com /als4gsig.

3. "Oregon State University Library Undergraduate Research Awards," accessed May 15, 2019, https://library.oregonstate.edu /awards/undergrad-research.

4. "Penn State University Libraries Undergraduate Research Award," accessed May 15, 2019, https:// libraries.psu.edu/about/awards-scholarships -internships-and-graduate-assistantships /university-libraries-undergraduate.

5. "Library Research Award for Undergraduates - University of Washington Libraries," accessed May 15, 2019, http://www.lib. washington.edu/researchaward.

6. "USC Libraries Research Award," accessed May 15, 2019, https://libraries. usc.edu/locations/special-collections/usc -libraries-research-award.

7. "Brandeis University Research Excellence Prize," accessed May 15, 2019 , http://www.brandeis.edu/library/research /research-excellence-prize.html.

8. LibGuide, https://guides.library. oregonstate.edu/gradcompetition.

9. See https://guides.library.oregonstate. edu/gradcompetition/onlinegallery. $\boldsymbol{n}$ 